\title{
Synthesis of Backbone-Engineered HIV Protease by Selective Chemical Ligation
}

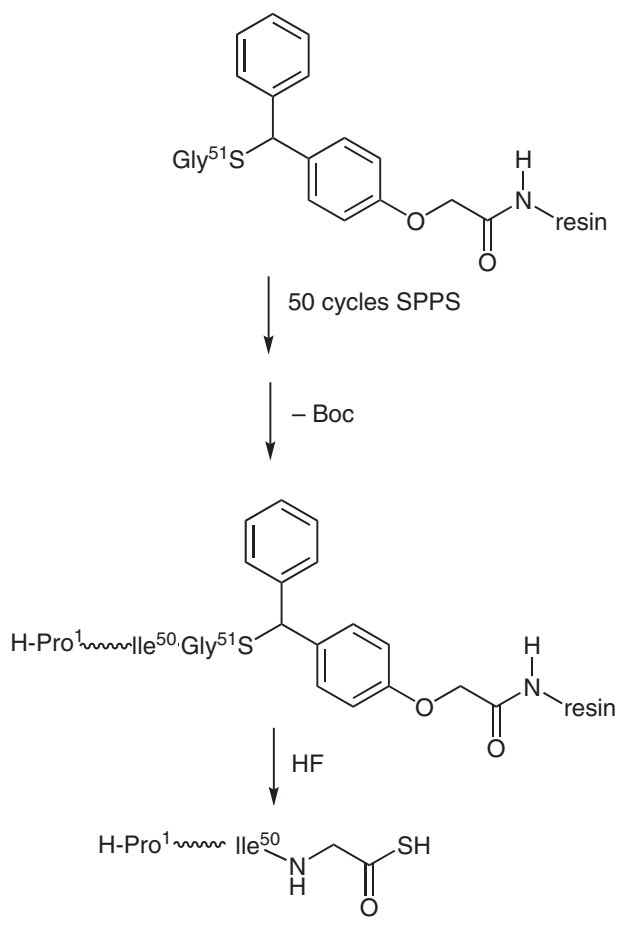

HIV-1 PR(1-50,Gly- $\alpha$ COSH)

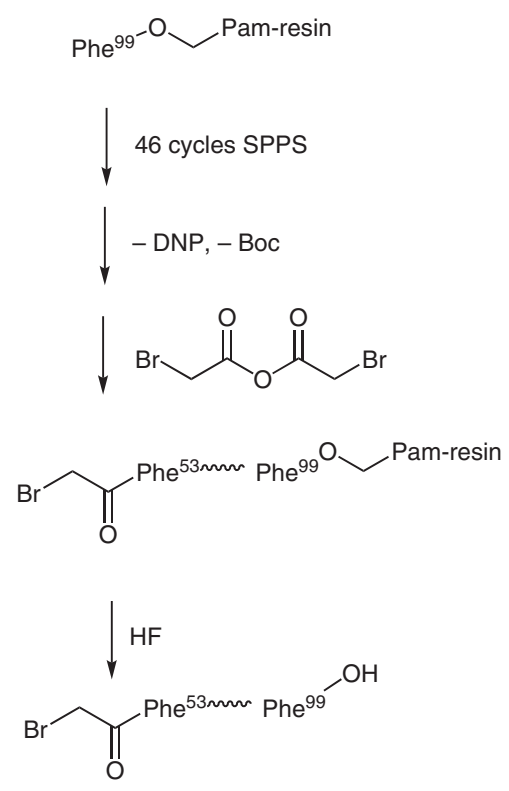

bromoacetyl(53-99)HIV-1 PR

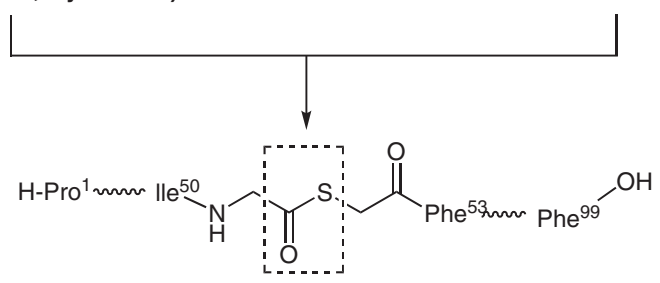

$\left[\left(\mathrm{NHCH}_{2} \mathrm{COSCH}_{2} \mathrm{CO}\right)^{51-52}\right] \mathrm{HIV}-1$ PR

Significance: The authors have developed a selective chemical ligation approach to the synthesis of protein analogues from large synthetic peptides. This method offers improved synthesis and concomitant introduction of new structural features into the protein. In addition, a number of interesting and important modifications of protein structures and syntheses of hybrid protein-nonprotein macromolecules were achieved.
Comment: A backbone-engineered HIV-1 protease was synthesized in high yield by joining two halves of the HIV-1 protease monomer polypeptide chain through mutually reactive functional groups, one on each segment. The ligation reaction was carried out in $6 \mathrm{M}$ guanidine hydrochloride, $0.1 \mathrm{M}$ sodium phosphate buffer at $\mathrm{pH} 4.3$, thereby eliminating the problem of limited solubility, a major drawback of the classical ligation approach. 